\title{
Aprender de microbiología desde la importancia de las bacterias promotoras de crecimiento vegetal. Una experiencia en la escuela primaria
}

\author{
Liliana Amado Rodríguez \\ Semillero de investigación Grupo WAIRA. Licenciatura en Ciencias Naturales y Educación Ambiental, \\ Universidad Pedagógica y Tecnológica de Colombia.Colombia.lilianaupto@gmail.com \\ Nidia Yaneth Torres Merchán \\ Facultad de Ciencias de la Educación. Licenciatura en Ciencias Naturales y Educación Ambiental. \\ Universidad Pedagógica y Tecnológica de Colombia.Colombia.nidia.torres@uptc.edu.co \\ Daniel Galindo Guerra (D) \\ Facultad de Ciencias. Universidad Pedagógica y Tecnológica de Colombia. Colombia. \\ daniel.galindo@uptc.edu.co
}

[Recibido: 10 agosto 2020. Revisado 15 septiembre 2020. Aceptado: 10 febrero 2021]

\begin{abstract}
Resumen: Este artículo presenta los resultados del componente didáctico en un proyecto que efectuó la caracterización bacteriana de las cepas seleccionadas para la germinación de la quinua (Chenopodium quinoa W. ). $\mathrm{Al}$ respecto se diseñó y desarrolló un módulo de aprendizaje en 6 sesiones, con 28 estudiantes de grado 5 de primaria de una institución oficial del departamento de Boyacá en Colombia, organizados en equipos de 4 estudiantes para facilitar la distribución del material. Se analizó las concepciones hacia los microrganismos antes y después de la experiencia. Se observó que los niños aprenden conceptos relacionados con la microbiología como medios de cultivos, diferencias entre bacterias y hongos, reproducción e importancia de las bacterias promotoras de crecimiento vegetal. Se resalta la importancia de abordar estos temas desde escenarios de la educación primaria, para comprender alternativas ecológicas sobre crecimiento vegetal.
\end{abstract}

Palabras clave: Enseñanza de la microbiología, Educación científica, Educación primaria

Learn about microbiology from the importance of growth promoting bacteria in primary school

Abstract: This article presents the results of the didactic component in a project that carried out the bacterial characterization of the strains selected for the germination of quinoa (Chenopodium quinoa W.). In this regard, a learning module was designed and developed in 6 sessions, with 28 students in grade 5 of primary school from an official institution of the department of Boyaca in Colombia, organized in teams of 4 students to facilitate the distribution of the material. Conceptions towards microorganisms were analyzed before and after the experience. It was observed that the children learn concepts related to microbiology such as culture media, differences between bacteria and fungi, reproduction and importance of plant growth promoting bacteria. The importance of addressing these issues from primary education settings is highlighted, to understand ecological alternatives on plant growth.

Keywords: Teaching of microbiology, Science education, Primary education

Para citar este artículo: Amado Rodríguez L., Torres Merchán N. Y. y Galindo Guerra D. (2021) Aprender de microbiología desde la importancia de las bacterias promotoras de crecimiento vegetal. Una experiencia en la escuela primaria. Revista Eureka sobre Enseñanza y Divulgación de las Ciencias 18(3), 3201. doi: 10.25267/Rev_Eureka_ensen_divulg_cienc.2021.v18.i3.3201 


\section{Introducción}

Las bacterias asociadas con las raíces de las plantas pueden generar diferentes mecanismos que afectan positivamente su desarrollo y crecimiento, produciendo sustancias promotoras del crecimiento vegetal, activando varias respuestas a nivel bioquímico, fisiológico y morfológico (Camelo et al. 2011). Estas son capaces de incrementar la resistencia de las plantas a diversos factores ambientales, ya que pueden inducir o suprimir la expresión de una amplia gama de genes. En este sentido, la aplicación de inoculantes bacterianos ha constituido una alternativa ecológica, que favorece la conservación del ambiente y el ecosistema, al implementar alternativas ecológicas sanas como el uso de rizobacterias promotoras del crecimiento vegetal, PGPR, por su sigla en inglés Plant Growth Promoting Rizobacteria (Moreno et al. 2018; Pérez et al. 2015). Por ello, se planteó en la investigación, la caracterización de seis cepas bacterianas, para ser utilizadas en cultivos de quinua; además se buscó fomentar una experiencia práctica para la enseñanza de la microbiología y sus aplicaciones en la agricultura con estudiantes de básica primaria, para facilitar la comprensión sobre el efecto positivo de los microorganismos en los ecosistemas y reconocer su contribución en aspectos como la regeneración (absorción) de nutrientes, la interacción de forma dinámica en los ciclos biogeoquímicos, lo cual permitió abordar relaciones Ciencia Tecnología y Sociedad CTS, sobre el efecto de los cultivos microbiológicos en el contexto ambiental y biológico.

En este sentido, se parte de promover el conocimiento científico adecuado sobre los aspectos básicos relacionados con los modos de acción de los microorganismos desde la educación primaria. Por ende, el propósito de este estudio fue desarrollar e implementar un módulo de intervención práctica para facilitar la comprensión de los estudiantes, sobre el conocimiento y los beneficios de los microorganismos, pues la enseñanza de la microbiología se ve enfrentada en ocasiones a las dificultades para explicar fenómenos biológicos en organismos que son invisibles a los ojos de los estudiantes, a esto se suma un gran número de términos que son necesarios para la explicación de las temáticas, pero de difícil comprensión (Durango, 2012). Por ejemplo, Redfern et al. (2013), investigaron la enseñanza de la microbiología en el contexto de la educación secundaria y señalan como esta ciencia ha presentado su evolución desde el uso de técnicas clásicas a un enfoque más molecular, pero difícilmente los estudiantes tienen la oportunidad de realizar experimentos, lo cual conduce a la generación de conceptos erróneos. También, Ballesteros et al. (2018), analizan las ideas que los alumnos entre 8 y 11 años tienen sobre los microorganismos e indica una concepción negativa y limitada de los microorganismos. Los estudiantes desconocen su importancia en la producción de medicamentos, alimentos y ciclos biogeoquímicos, (Byrne et al. 2009; Harms 2002; Karadon y Şahin 2010). En el mismo sentido, Karadon y Şahin (2010), revelan que las principales fuentes de información sobre el efecto de los microorganismos son lo aprendido en la escuela o lo emitido por los medios de comunicación, sin embargo, en muy pocos casos el tema es abordado en la escuela primaria, por lo que se deja como única fuente informativa los medios de comunicación, generándose errores conceptuales; aspecto similar a lo que sucede con las percepciones que tienen los estudiantes sobre especies no carismáticas, (Torres-Merchán et al. 2018).

Por todo lo anterior, en Marcos-Merino et al. (2019), describen la necesidad de abordar prácticas para la enseñanza de conceptos microbiológicos básicos a maestros en formación inicial de educación primaria, aspecto que favorece la apropiación conceptual y puede evitar errores conceptuales en los estudiantes (Pedreros y Torres 2020). Al respecto Faccio et al. (2013); Harms (2002), recomiendan la inclusión de prácticas experimentales sobre la enseñanza de los microorganismos, para mejorar su conocimiento. Por ello, se sugiere que debe incluirse en el currículo el estudio de los microorganismos y su influencia en la vida 
diaria y sus aplicaciones en campos como la agricultura, la medicina y la biotecnología, (Byrne et al. 2009; Redfern et al. 2013). Así mismo, Ballesteros et al. (2018); Byrne et al. (2009) resaltan la necesidad de intervenciones educativas más cuidadosas para ampliar el conocimiento de los microorganismos, su importancia y su papel en la naturaleza.

En este sentido, esta investigación desarrolló una intervención didáctica para que los estudiantes de básica primaria conozcan el papel de las bacterias en la agricultura y su función en alternativas ecológicas sanas como es el uso de biofertilizantes a base de bacterias promotoras de crecimiento PGPR, debido a que la aplicación de estos microorganismos resulta beneficiosa en el rendimiento de cultivos, como la quinua (Chenopodium quinoa W.) considerada un alimento con alto valor nutritivo por la Organización de las Naciones Unidas para la Alimentación y la Agricultura (FAO) (García-Parra et al. 2020).

Por ejemplo, Jones y Rua (2006); Williams y Gillen (1991), indican que los estudiantes comienzan a desarrollar conceptos tempranos sobre los fenómenos de la ciencia biológica antes de la instrucción formal y entran a la escuela con explicaciones y entendimientos individuales, por lo que recomiendan efectuar ejercicios de socialización adecuada para conocer la ciencia como fenómeno social, este aspecto resulta preciso para efectuar conexiones entre los fenómenos observables y las ideas subyacentes, en este caso para promover el conocimiento de los estudiantes hacia los microorganismos, pues en muchos de los casos, su inserción es escasa en estos escenarios, lo cual determina el tipo de actitudes negativas hacia los microrganismos que tienen incidencia en conceptos erróneos (Milandri, 2004); así como dificultades en la transición entre los niveles micro y macro de conceptualización de las ciencias. En este sentido, este estudio planteó como preguntas ¿Qué impacto tiene una intervención didáctica desde el abordaje de un módulo de aprendizaje relacionado con el tema de microorganismos, en niños de grado quinto de básica primaria? ¿Hay cambios en la comprensión en el reconocimiento del papel fundamental de los microorganismos en el medio ambiente y en las actividades humanas?.

\section{Metodología}

En esta experiencia de aula estuvieron implicados las dos primeras autoras quienes efectuaron dicho estudio como parte de un proyecto de investigación sobre caracterización de cepas bacterianas para el crecimiento de la Quinua.

\section{Participantes}

Los estudiantes participantes en el estudio, fueron 28 estudiantes de un colegio oficial de Duitama en el departamento de Boyacá - Colombia, quienes cursaban el grado quinto que corresponde al último grado de la educación primaria, con un rango de edad de 10 a 12 años, de los cuales 17 son niñas y 11 son niños.

\section{La investigación se desarrolló con las siguientes etapas}

- En primer lugar, se efectuó un diagnóstico mediante un cuestionario de 5 preguntas, para conocer las concepciones que tienen los estudiantes sobre los microrganismos, desde actividades que se describen en la tabla 1. 
Tabla 1. Descripción de las actividades elaboradas en el cuestionario inicial y sus objetivos.

\begin{tabular}{|c|c|c|c|}
\hline Temas & Descripción de la pregunta & Objetivos & $\begin{array}{l}\text { Número de } \\
\text { la pregunta }\end{array}$ \\
\hline \multirow[t]{2}{*}{$\begin{array}{l}\text { Conceptualización y } \\
\text { descripción de los } \\
\text { microorganismos }\end{array}$} & $\begin{array}{l}\text { Se presenta a los estudiantes una lectura } \\
\text { denominada "Entra un bebé en el mundo de los } \\
\text { microrganismos", basado en el proyecto e-bug, texto } \\
\text { que pretendió describir como desde el momento } \\
\text { del nacimiento se entra en contacto con } \\
\text { microorganismos. Al final se plantea la siguiente } \\
\text { pregunta ¿Para ti qué son los microorganismos? }\end{array}$ & $\begin{array}{c}\text { Reconocer que los } \\
\text { microorganismos } \\
\text { hacen parte de nuestra } \\
\text { vida }\end{array}$ & 1 \\
\hline & $\begin{array}{l}\text { Se les solicita a los estudiantes que representen a } \\
\text { través de un dibujo un hongo, una bacteria o un } \\
\text { virus y se plantea que respondan ¿Por qué dibujo } \\
\text { ese tipo de microorganismo? }\end{array}$ & $\begin{array}{c}\text { Reconocer } \\
\text { representaciones } \\
\text { gráficas que tienen los } \\
\text { estudiantes de los } \\
\text { microorganismos }\end{array}$ & 2 \\
\hline $\begin{array}{l}\text { Reproducción de los } \\
\text { microorganismos }\end{array}$ & $\begin{array}{l}\text { Se presentó un texto que destaca como los } \\
\text { microorganismos tienen la capacidad de habitar } \\
\text { todos los tipos de ambientes, participan en } \\
\text { procesos metabólicos, ecológicos y biotecnológicos, } \\
\text { además de esto, permanecen en interacción } \\
\text { constante con las plantas, los animales y los seres } \\
\text { humanos. Son de gran importancia en la } \\
\text { descomposición de desechos orgánicos, regulación } \\
\text { de ciclos biogeoquímicos, retención y liberación de } \\
\text { nutrientes en las plantas, control de plagas agrícolas, } \\
\text { síntesis de alimentos y productos farmacéuticos } \\
\text { entre muchos otros (Montaño et al. 2010), por lo } \\
\text { cual es necesaria su reproducción. A partir de lo } \\
\text { anterior se planteó la pregunta ¿Cómo crees que } \\
\text { se reproducen los microrganismos? }\end{array}$ & $\begin{array}{l}\text { Indagar sobre las } \\
\quad \text { formas de } \\
\text { reproducción de los } \\
\text { microorganismos }\end{array}$ & 3 \\
\hline $\begin{array}{c}\text { Importancia de las } \\
\text { bacterias }\end{array}$ & $\begin{array}{l}\text { Se tomó una lectura de Pedraza et al. (2010), para } \\
\text { abordar los beneficios de las bacterias promotoras } \\
\text { de crecimiento vegetal (PGPR) que intervienen en } \\
\text { la calidad y rendimiento de distintos cultivos } \\
\text { agrícolas. Desde esta lectura se les cuestionó } \\
\text { ¿Cuáles son los beneficios de los microorganismos? }\end{array}$ & $\begin{array}{l}\text { Identificar los } \\
\text { beneficios de los } \\
\text { microorganismos. }\end{array}$ & 4 \\
\hline $\begin{array}{c}\text { Quinua } \\
\text { (Chenopodium quinoa) }\end{array}$ & $\begin{array}{l}\text { Durante las últimas décadas, la Organización de las } \\
\text { Naciones Unidas para la Alimentación y la } \\
\text { Agricultura (FAO), han promovido el desarrollo de } \\
\text { cultivos como la quinua debido a la adaptabilidad } \\
\text { que esta presenta bajo diferentes condiciones } \\
\text { edafoclimática y su alto valor nutricional. Por ello, } \\
\text { se cuestiona a los estudiantes sobre algún } \\
\text { conocimiento de la quinua (Chenopodium quinoa W.) } \\
\text { con la pregunta ¿Sabes qué es la quinua? }\end{array}$ & $\begin{array}{l}\text { Reconocer la } \\
\text { importancia de quinua } \\
\text { (Chenopodium quinoa } \\
\text { W.) }\end{array}$ & 5 \\
\hline
\end{tabular}

Diseño e Implementación del módulo de aprendizaje

A partir de los resultados del diagnóstico se diseñó y desarrollo el módulo de aprendizaje denominado: El mundo de los microorganismos, que tuvo como fin, orientar a los estudiantes sobre características, reproducción y uso de los microorganismos. Este se implementó en 4 sesiones cada una de 50 minutos; los 28 estudiantes se organizaron aleatoriamente en 7 grupos cada uno de ellos con 4 estudiantes. Se trabajó la preparación de medios del cultivo, la reproducción y la observación convencional a nivel macro (colonias) y microscópico. 
Tabla 2. Sesiones y actividades desarrolladas en la implementación del módulo de aprendizaje.

\begin{tabular}{|c|c|c|c|}
\hline Sesión & Actividad & Objetivo & Descripción de la actividad \\
\hline $\begin{array}{l}\text { 1. ¿Cómo } \\
\text { preparar medios } \\
\text { de cultivo? }\end{array}$ & $\begin{array}{l}\text { Presentación del } \\
\text { vídeo }\end{array}$ & $\begin{array}{llr}\text { Ilustrar } & \text { a } & \text { los } \\
\text { estudiantes } & \text { acerca } \\
\text { de los } & \text { principios } \\
\text { básicos } & \text { que } & \text { se } \\
\text { requieren } & \text { para } & \text { la } \\
\text { preparación } & \text { de } & \text { los } \\
\text { medios de cultivo. }\end{array}$ & $\begin{array}{l}\text { Se presentó un vídeo titulado Cómo cultivar } \\
\text { microorganismos, hecho por los autores. En este } \\
\text { recurso se muestra los pasos a seguir en la } \\
\text { elaboración de un medio de cultivo para } \\
\text { bacterias y hongos. }\end{array}$ \\
\hline $\begin{array}{l}\text { 2. Cultivar } \\
\text { microorganismos }\end{array}$ & $\begin{array}{l}¿ V e m o s \text { todo lo que } \\
\text { hay en el ambiente? }\end{array}$ & $\begin{array}{l}\text { Utilizar diferentes } \\
\text { objetos para } \\
\text { comprobar dónde } \\
\text { se encuentran los } \\
\text { microorganismos. }\end{array}$ & $\begin{array}{l}\text { Previo a la inoculación de microorganismos se } \\
\text { les solicita a los estudiantes que hagan una } \\
\text { descripción detallada de lo que observan, con el } \\
\text { fin de realizar una comparación antes y después } \\
\text { de la inoculación. } \\
\text { En esta parte, los estudiantes escribieron las } \\
\text { características observadas en su mano, tales } \\
\text { como forma, color y tamaño. Luego para la } \\
\text { inoculación de los microorganismos en medios } \\
\text { de cultivo sólidos, los estudiantes tomaron el } \\
\text { dedo índice pasándolo sobre el agar nutritivo y } \\
\text { el agar PDA (papa - dextrosa - agar). A } \\
\text { continuación, los estudiantes se lavaron las } \\
\text { manos, teniendo en cuenta las normas de } \\
\text { asepsia, y nuevamente pasaron el dedo índice } \\
\text { por los dos medios estériles. } \\
\text { La actividad se repite al pedir a los estudiantes } \\
\text { que efectúen una descripción de las } \\
\text { características observadas al bostezar en el } \\
\text { espejo y que posteriormente hagan un cultivo } \\
\text { de bostezo en la caja de Petri con agar nutritivo } \\
\text { y PDA. } \\
\text { Finalmente, se toman plántulas de quinua } \\
\text { previamente sembradas y se les pide a los } \\
\text { estudiantes que realicen la descripción de la } \\
\text { plántula, teniendo en cuenta la raíz y su } \\
\text { alrededor. Una vez terminada la observación y } \\
\text { descripción se les solicita a los estudiantes que } \\
\text { pasen la raíz de la plántula, primero por la caja } \\
\text { de Petri que contiene agar nutritivo y luego por } \\
\text { la de PDA. }\end{array}$ \\
\hline \multirow{3}{*}{$\begin{array}{l}\text { 3. Reconoce los } \\
\text { microorganismos }\end{array}$} & $\begin{array}{l}\text { Actividad } 1 . \\
\text { Descripción } \\
\text { macroscópica de las } \\
\text { cajas inoculadas. }\end{array}$ & \multirow{3}{*}{$\begin{array}{l}\text { Identificar qué tipos } \\
\text { de microorganismos } \\
\text { se desarrollaron en } \\
\text { los medios de } \\
\text { cultivo }\end{array}$} & $\begin{array}{l}\text { Pasados } 4 \text { días de la inoculación en las cajas } \\
\text { estériles de Petri, los estudiantes realizaron la } \\
\text { descripción de lo observado en las cajas. }\end{array}$ \\
\hline & $\begin{array}{l}\text { Actividad } 2 . \\
\text { Tinción de Gram. }\end{array}$ & & $\begin{array}{l}\text { Para cada caja inoculada en la sesión dos, se } \\
\text { hizo una tinción de gram para la observación e } \\
\text { identificación de bacterias. }\end{array}$ \\
\hline & $\begin{array}{l}\text { Actividad } 3 . \\
\text { Tinción con Azul } \\
\text { algodón de } \\
\text { lactofenol. }\end{array}$ & & $\begin{array}{l}\text { Para cada caja inoculada además de la tinción de } \\
\text { gram, se realizó por separado tinción con azul } \\
\text { algodón de lactofenol para la observación de } \\
\text { hongos. } \\
\text { La función de cada una de las tinciones fue } \\
\text { explicado a los estudiantes y ellos reportaron lo } \\
\text { identificado en cada tipo de tinción. }\end{array}$ \\
\hline
\end{tabular}


Tabla 2. Continuación

\begin{tabular}{|c|c|c|c|}
\hline Sesión & Actividad & Objetivo & Descripción de la actividad \\
\hline \multirow{2}{*}{$\begin{array}{l}\text { 3. Reconoce los } \\
\text { microorganismos }\end{array}$} & $\begin{array}{l}\text { Actividad } 4 . \\
\text { Observación al } \\
\text { microscopio. }\end{array}$ & \multirow{2}{*}{$\begin{array}{l}\text { Identificar qué tipos } \\
\text { de microorganismos } \\
\text { se desarrollaron en } \\
\text { los medios de } \\
\text { cultivo }\end{array}$} & $\begin{array}{l}\text { Realizadas las tinciones se hizo una observación } \\
\text { microscópica que fue proyectada en un } \\
\text { televisor. }\end{array}$ \\
\hline & $\begin{array}{l}\text { Actividad } 5 . \\
\text { Resultados y } \\
\text { discusión. }\end{array}$ & & $\begin{array}{l}\text { Los estudiantes analizan y discuten qué } \\
\text { observaron antes y después de inocular las cajas } \\
\text { y responden a la pregunta ¿qué sucedió y por } \\
\text { qué? }\end{array}$ \\
\hline \multirow{2}{*}{$\begin{array}{l}\text { 4. Beneficios y } \\
\text { perjuicios de los } \\
\text { microrganismos }\end{array}$} & $\begin{array}{l}\text { Actividad } 1 . \\
\text { Vídeo sobre } \\
\text { bacterias de } \\
\text { crecimiento vegetal }\end{array}$ & \multirow{2}{*}{$\begin{array}{l}\text { Reconocer los } \\
\text { beneficios e } \\
\text { implicación de los } \\
\text { microorganismos en } \\
\text { el sector agrícola. }\end{array}$} & $\begin{array}{l}\text { Para la realización del debate se compartió con } \\
\text { los estudiantes material que funcionó como } \\
\text { argumento para la defensa u oposición del tema } \\
\text { Beneficios y perjuicios de los microorganismos. Primero } \\
\text { se proyectó un vídeo titulado Efectos de las } \\
\text { bacterias promotoras de crecimiento en las plantas. } \\
\text { Seguido se realizó una lectura sobre los } \\
\text { beneficios y perjuicios de los microorganismos }\end{array}$ \\
\hline & $\begin{array}{l}\text { Actividad } 2 . \\
\text { Debate de las } \\
\text { lecturas "beneficios } \\
\text { y perjuicios de los } \\
\text { microorganismos" }\end{array}$ & & $\begin{array}{l}\text { Por último, se discutió la importancia de los } \\
\text { microorganismos en cultivos como la quinua y } \\
\text { su relevancia a nivel nutricional. Lo anterior } \\
\text { desde los resultados obtenidos en el } \\
\text { componente biológico sobre el Análisis de la } \\
\text { potencialidad del uso de bacterias promotoras de } \\
\text { crecimiento vegetal en cultivo de quinua (Chenopodium } \\
\text { quinoa } W \text {.) }\end{array}$ \\
\hline
\end{tabular}

\section{Evaluación de la experiencia}

Para evaluar las contribuciones didácticas con base a la implementación del módulo de aprendizaje se aplicó un cuestionario final que fue confrontado con el cuestionario inicial. En primer lugar se clasificaron las diferentes respuestas de cada pregunta, como se presentan en las tablas 3,4,7, y 8. Para el análisis, se realizó la prueba de Fisher para tablas 2x2 (Siegel y Castellan, 1998). Esta prueba determina si el grupo pre y el grupo post-test difieren en la proporción de las respuestas acertadas en cada pregunta. A partir de lo anterior, se obtuvo el valor de $p$ para analizar efectos de la intervención.

Se organizaron los resultados en una base de datos con el listado de alumnos y las preguntas asignando 1 para acertadas y 0 en no acertadas en el pre- y post-test; lo anterior para realizar:

- Un análisis descriptivo con el fin de obtener el porcentaje de alumnos con respuestas probables en cada pregunta del pre y post-test.

- Comparaciones de las proporciones de estudiantes con respuestas en el pre y en el post-test para cada pregunta con la prueba de Fisher.

$\mathrm{Al}$ respecto se plantearon las hipótesis:

- Hipótesis nula (Ho): el grupo pre- y el grupo post-test no presentan diferencias significativas en la proporción de las respuestas acertadas (dadas en cada pregunta) $(\mathrm{p}>=0,05)$.

- Hipótesis alterna $(\mathrm{Ha}$ ): el grupo pre- y el grupo post-test si presentan diferencias significativas en la proporción de las respuestas acertadas (dadas en cada pregunta) $(\mathrm{p}<=0,05)$. 


\section{Resultados y discusión}

\section{Diagnóstico. Representaciones de los estudiantes acerca de los microrganismos}

Con la implementación del cuestionario inicial, se encontró que los estudiantes en un 89,28\% consideraron que los microorganismos son hongos y bacterias (tabla 3), con una predilección en la representación gráfica de los hongos; alrededor del 3,57\% creen que estos son animales y un 7\% no señala ninguna opción. Por lo cual, asumen a los hongos y bacterias como agentes dañinos y nocivos, causantes de enfermedades. En estudios de (Byrne et al. 2009; Jones y Rua 2006), se encontró que los niños asignan funciones perjudiciales y están asociados a la producción de enfermedades.

Tabla 3. Respuestas a la pregunta 1 , ¿Para ti qué son los microorganismos?

\begin{tabular}{|l|c|c|}
\hline \multicolumn{1}{|c|}{ Opciones de repuesta } & $\begin{array}{c}\text { Total de } \\
\text { respuestas }\end{array}$ & Porcentaje \\
\hline Plantas & $0 / 28$ & $0 \%$ \\
\hline Animales & $1 / 28$ & $3,57 \%$ \\
\hline Hongos y bacterias & $25 / 28$ & $89,28 \%$ \\
\hline Ninguna de las anteriores & $2 / 28$ & $7,14 \%$ \\
\hline
\end{tabular}

En relación a las representaciones que hacen los estudiantes se evidenció que el 78,57\% tiene preferencia por los hongos (ver tabla 4), de la misma manera en la figura 1, se muestra que los estudiantes asocian los hongos macroscópicos con lo observado en su contexto, pero aún hace falta familiarizarse con los hongos microscópicos; así mismo, lo relacionan con enfermedades de la piel. Por ejemplo, en la figura 1, se representa la presencia de bacterias en un tubo de agua, y se indica que éstas causan enfermedades en el ser humano. Finalmente, se muestra un invertebrado señalándolo como bacteria. También Byrne et al. (2009) encontró que los niños de siete años clasificaron los microorganismos como animales o como entidades abstractas, representándolos como pequeños insectos y bichos; sin embargo, se infiere la necesidad de resaltar los beneficios y el papel biológico que tienen distintos tipos de bacterias, un ejemplo claro son las bacterias promotoras de crecimiento vegetal.

Se observó cómo los estudiantes clasificaron los microorganismos como animales, bichos, gérmenes, asociados a suciedad, y enfermedades. Los describen como seres diminutos a excepción de los hongos macroscópicos. En los dibujos hacen referencia a hábitats ocupados por microorganismos con predominio de la asociación entre microorganismos y lugares sucios. También se representa que los microorganismos se encuentran en partes específicas del cuerpo en este caso boca y nariz. Esto coincide con estudios de (Byrne et al. 2009; Karadon y Şahin 2010).

Tabla 4. Respuestas a la pregunta 2, ¿Qué dibujaron los estudiantes?

\begin{tabular}{|l|c|c|}
\hline \multicolumn{1}{|c|}{ Opciones de repuesta } & $\begin{array}{c}\text { Total de } \\
\text { respuestas }\end{array}$ & Porcentaje \\
\hline Hongos & $22 / 28$ & $78,57 \%$ \\
\hline Bacterias & $5 / 28$ & $17,85 \%$ \\
\hline Virus & $0 / 28$ & $0 \%$ \\
\hline Ninguna de las anteriores & $1 / 28$ & $3,57 \%$ \\
\hline
\end{tabular}


Las anteriores percepciones permiten inferir la necesidad de guiar a los estudiantes en el reconocimiento de otros tipos de hongos mediante la observación microscópica, al igual que algunas de sus funciones y aplicaciones, tal es el caso de los hongos de micorriza arbuscular (HMA) que facilitan el crecimiento de las plantas aún en condiciones de estrés como sequía, salinidad, altas y bajas temperaturas mejorando la nutrición al aumentar la disponibilidad y movimiento de algunos nutrientes (Begum et al. 2019).

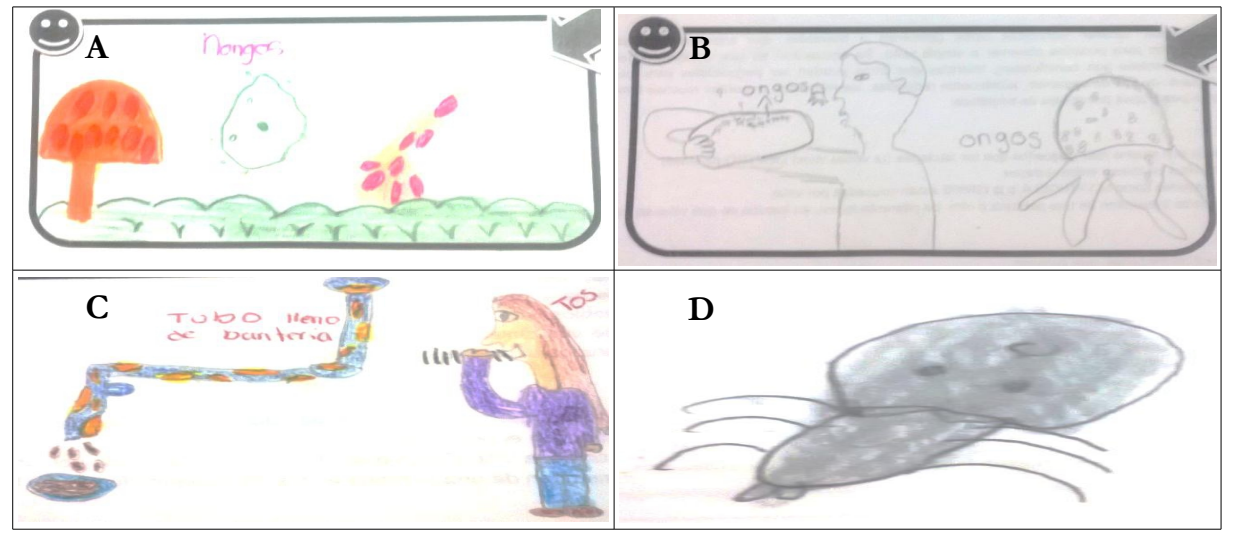

Figura 1. Representación gráfica (hongos y bacterias) de algunos estudiantes del grado quinto de primaria. A: Representación de hongos macroscópicos. B: Representación de hongo que afecta la piel. C: Tubo contaminado con bacterias que produce tos y estornudo en los humanos. D: Dibujo de una bacteria similar a un invertebrado.

Frente a la pregunta 2, en la que se les pedía a los estudiantes que justificaran ¿por qué hicieron dicha representación? el 17,85\% indicaron que dibujaron bacterias y hongos. Las respuestas de los estudiantes fueron agrupadas en dos categorías: bacterias que causan enfermedades y hongos que causan enfermedades, se hace notable asociaciones entre humanos y microorganismos, pero generalmente restringidos a aspectos negativos.

En la tabla 5, se presentan ejemplos de las respuestas dadas por algunos de los estudiantes en la pregunta $\mathrm{N}^{\circ} 2$. En este sentido, la denominación E1, hace referencia al estudiante 1 con la respuesta emitida.

Tabla 5. Respuesta de la actividad 2, sobre conceptualización de los microorganismos.

\begin{tabular}{|c|c|c|}
\hline Estudiante & Respuesta del estudiante & Categoría \\
\hline E1 & $\begin{array}{l}\text { "La bacteria es una especie como de animales y siempre salen de los } \\
\text { charcos y causan enfermedades" }\end{array}$ & \multirow{4}{*}{$\begin{array}{l}\text { Bacterias que causan } \\
\text { enfermedades }\end{array}$} \\
\hline E4 & $\begin{array}{l}\text { "Es una bacteria en forma de espiral y la elegí porque es peligrosa y } \\
\text { porque puede causar enfermedades que pueden matar a una persona sin } \\
\text { darse cuenta que es una bacteria" }\end{array}$ & \\
\hline E26 & $\begin{array}{l}\text { "Es un tubo lleno de bacterias que contaminan el agua y cuando lo } \\
\text { tomamos nos enfermamos" }\end{array}$ & \\
\hline E7 & $\begin{array}{l}\text { "Porque un día yo iba para el hospital y vi un señor con granos por todo } \\
\text { el cuerpo y dijo que eran bacterias" }\end{array}$ & \\
\hline E11 & $\begin{array}{l}\text { "Dibuje un hongo porque cuando uno los toca y los come pueden } \\
\text { generar una enfermedad terrible" }\end{array}$ & \multirow{5}{*}{$\begin{array}{l}\text { Hongos causantes de } \\
\text { enfermedades }\end{array}$} \\
\hline E14 & $\begin{array}{l}\text { "Dibuje un hongo porque es muy malo para la salud y puede producir } \\
\text { cáncer y más enfermedades que afectan la vida" }\end{array}$ & \\
\hline E6 & $\begin{array}{l}\text { "Dibuje un hongo porque están al lado de mi casa, estos están muy } \\
\text { unidos a los arboles grandes y son amarillos con puntos de colores" }\end{array}$ & \\
\hline E18 & $\begin{array}{l}\text { "Es un hongo porque es malo para la salud y puede enfermar a la gente } \\
\text { y matarlos en el hospital y es también malo para los bebes" }\end{array}$ & \\
\hline E21 & $\begin{array}{l}\text { "Dibuje un hongo porque a veces se desarrollan en nuestro cuerpo y } \\
\text { toca tomar pastas para poderlos quitar" }\end{array}$ & \\
\hline
\end{tabular}


Además de ello, el 18\% de los estudiantes reconocen solo los hongos macroscópicos por su forma y color. El 11\% de los estudiantes no indicaron respuesta.

En cuanto a la pregunta ¿Cómo crees que se reproducen los microorganismos? Se sintetizan las principales respuestas, en la tabla 6 , en tres categorías una relacionada con la reproducción sexual, porque generalmente los niños comentan que la reproducción es similar a la de los humanos. Reproducción asexual porque implícitamente hacen referencia a la fisión binaria, utilizando términos como "las bacterias se parten por la mitad", y una tercera categoría recoge aquellas respuestas donde los niños indican que la reproducción se da por contaminación; es decir abordan aspectos sobre los medios y las condiciones para la reproducción, esta categoría ha sido llamada generación espontánea debido a que durante siglos se creía que los seres vivos podrían surgir sin la intervención de progenitores semejantes a ellos (Acevedo-Díaz et al., 2016).

Tabla 6. Respuesta de la pregunta número 3, sobre reproducción de los microorganismos.

\begin{tabular}{|c|c|c|c|c|}
\hline Estudiante & Ejemplos de Respuesta & Categoría & $\begin{array}{c}\text { Número } \\
\text { de } \\
\text { respuestas }\end{array}$ & Porcentaje \\
\hline E1 & "Se reproducen al igual que los humanos" & \multirow{3}{*}{ Reproducción sexual } & \multirow{3}{*}{$15 / 28$} & \multirow{3}{*}{$53,57 \%$} \\
\hline E15 & $\begin{array}{l}\text { "Se reproducen con una bacteria femenina y otra } \\
\text { masculina y hacen otra bacteria chiquita" }\end{array}$ & & & \\
\hline E24 & $\begin{array}{l}\text { "Los microorganismos se reproducen igual que } \\
\text { mis papas" }\end{array}$ & & & \\
\hline E2 & "Crecen en el barro, en la basura y en la tierra" & \multirow{5}{*}{ Generación espontanea } & \multirow{5}{*}{$5 / 28$} & \multirow{5}{*}{$17,85 \%$} \\
\hline E7 & "De los desechos del cuerpo" & & & \\
\hline E8 & "Se reproducen de la comida que votamos" & & & \\
\hline E21 & $\begin{array}{l}\text { "Los microorganismos se reproducen por cosas } \\
\text { que no se recogen como la basura" }\end{array}$ & & & \\
\hline E26 & $\begin{array}{l}\text { "Los microorganismos se reproducen en las } \\
\text { alcantarillas, por el agua sucia" }\end{array}$ & & & \\
\hline E12 & "Ellos se reproducen partiéndose por la mitad" & \multirow{3}{*}{ Reproducción asexual } & \multirow{3}{*}{$2 / 28$} & \multirow{3}{*}{$7,14 \%$} \\
\hline E18 & $\begin{array}{l}\text { "Es una bolita y a esa bolita le sale una más } \\
\text { pequeña y de esa sale otra más pequeña" }\end{array}$ & & & \\
\hline $\mathrm{E} 20$ & "De una bacteria salen muchas bacterias" & & & \\
\hline
\end{tabular}

En relación a la reproducción de los microorganismos, se evidencio que el 17,85\% de los estudiantes creen que los microorganismos se reproducen en lugares contaminados, otros hacen referencia al tipo de reproducción asexual o sexual y nuevamente en las respuestas, los estudiantes asocian a los microorganismos con enfermedades, suciedad e impureza (Karadon y Şahin 2010). El 7,14\% de los estudiantes comprenden que los microorganismos se reproducen asexualmente, esto se infiere de repuestas como la del E12 que indica se reproducen partiéndose por la mitad. El 53,57\% de los estudiantes creen que los microorganismos se reproducen sexualmente, como por ejemplo E1, indica Se reproducen igual que los bumanos. El $21,42 \%$ de los estudiantes no respondieron a la pregunta. Este tipo de respuesta dan cuenta de la posibilidad de discutir el tema de la reproducción, haciendo énfasis en las diferencias que presentan los organismos que tienen reproducción sexual y asexual, al igual de cómo se transfiere la información genética en los microrganismos, temas que deberían enfocarse en estudios sobre enseñanza de la microbiología. 
En cuanto a la pregunta 4, ¿Qué otros beneficios de las bacterias conoces?, se obtuvo que el $64,28 \%$, de los estudiantes no conocen ningún beneficio de las bacterias, (ver tabla 7), aspecto que da cuenta de abordar el tema en escenarios de educación primaria.

Tabla 7. Respuestas a la pregunta 4, ¿Qué otros beneficios de las bacterias conoces?

\begin{tabular}{|l|c|c|}
\hline Opciones de repuesta & $\begin{array}{c}\text { Total de } \\
\text { respuestas }\end{array}$ & Porcentaje \\
\hline Conocen beneficios & $5 / 28$ & $17,85 \%$ \\
\hline $\begin{array}{l}\text { No conocen } \\
\text { beneficios }\end{array}$ & $18 / 28$ & $64,28 \%$ \\
\hline $\begin{array}{l}\text { No saben no } \\
\text { responden }\end{array}$ & $5 / 28$ & $17,84 \%$ \\
\hline
\end{tabular}

Para finalizar en la pregunta 5 ¿sabes qué es la quinua?, cuyo objetivo era identificar si los estudiantes tenían conocimiento sobre la quinua (Chenopodium quinoa W.), se encontró que el $28,57 \%$ indican que la quinua es una planta; el 21,42\% considera que es un animal; el 17,85\% una bacteria y $32,14 \%$ no responden, (ver tabla 8 ).

Tabla 8. Respuestas a la pregunta 5 , ¿Sabes qué es la quinua?

\begin{tabular}{|l|c|c|}
\hline Opciones de repuesta & $\begin{array}{c}\text { Total de } \\
\text { respuestas }\end{array}$ & Porcentaje \\
\hline Planta & $8 / 28$ & $28,57 \%$ \\
\hline Animal & $6 / 28$ & $21,42 \%$ \\
\hline Bacteria & $5 / 28$ & $17,85 \%$ \\
\hline No sabe no responde & $9 / 28$ & $32,14 \%$ \\
\hline
\end{tabular}

Las respuestas del cuestionario inicial, dejan ver la importancia de abordar el tema en la educación primaria para comenzar desde edades tempranas con conceptos sobre microbiología, aspecto que brinda la oportunidad de valorar las aplicaciones y beneficios de los microrganismos.

\section{Implementación del módulo}

A continuación, se describen los resultados del módulo:

Sesión 1: ¿Cómo preparar medios de cultivo?

Mediante el vídeo titulado "cómo cultivar microorganismos" de 3'38", elaborado por los autores, se presentaron los pasos que se requieren para la preparación de medios de cultivos en el desarrollo de hongos y bacterias, en este se indicaron temas como nutrientes requeridos en la reproducción de los microorganismos (hongos y bacterias), importancia de la esterilización y diferencia entre los nutrientes requeridos para el desarrollo de hongos y bacterias.

$\mathrm{Al}$ respecto, los estudiantes formulan preguntas como: ¿Qué es esterilizar?, ¿Por qué se deben esterilizar las cosas?, ¿Se puede hacer medio de cultivo en la casa?, ¿El agar es malo? ¿Qué comen los microorganismos? Como parte de la retroalimentación se realizó la discusión acerca de ¿Por qué es importante la asepsia de nuestro cuerpo?, ¿Por qué debemos lavar los alimentos antes de consumirlos?.

Todos los estudiantes elaboraron un dibujo indicando los pasos para la elaboración de un medio de cultivo. Algunos dibujos se muestran en la figura 2. 


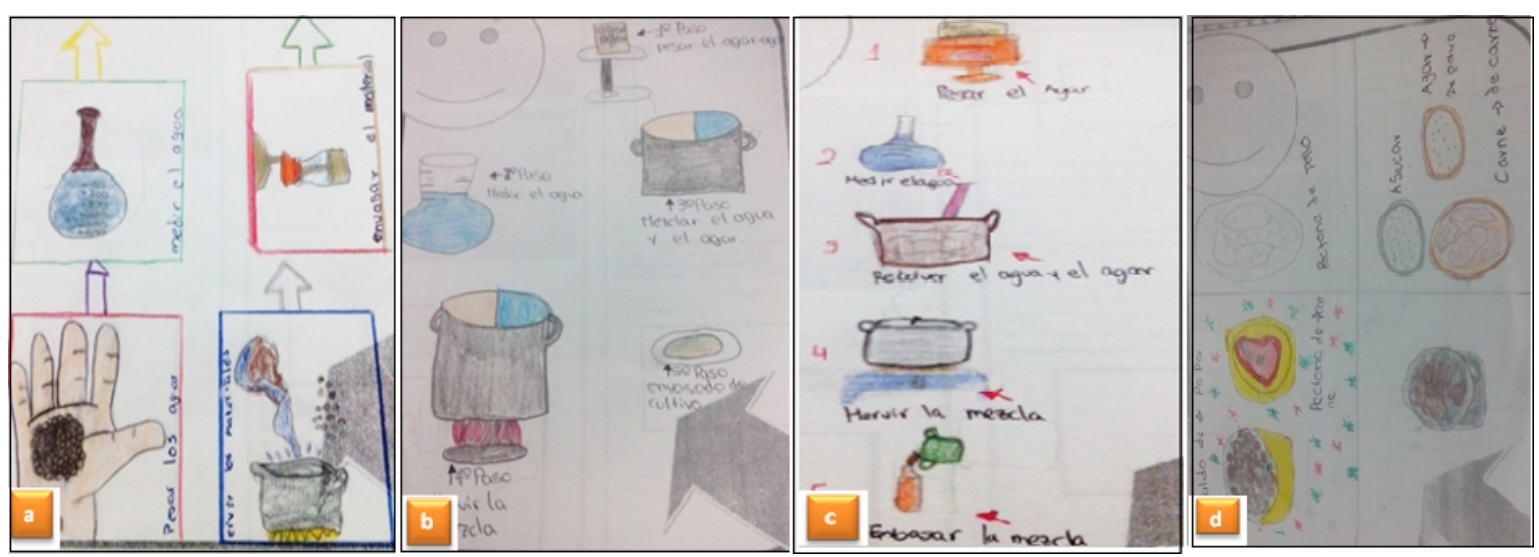

Figura 2. Diagramas sobre preparación de medios de cultivo. Se observan pasos como pesar el agar, medir el agua, envasar y esterilizar los materiales y envasar el material.

\section{Sesión 2: Cultivar microorganismos}

En esta actividad, se les pide a los estudiantes describir sus manos a nivel microscópico, luego se solicita que pasen un dedo en el cultivo. La intención es guiarlos hacia la presencia de microorganismos y la importancia del lavado de manos. Esta misma actividad se repitió con el bostezo en el espejo y el bostezo en la caja de Petri, la observación de la raíz de la planta e inoculación de la misma, ver figura 3.
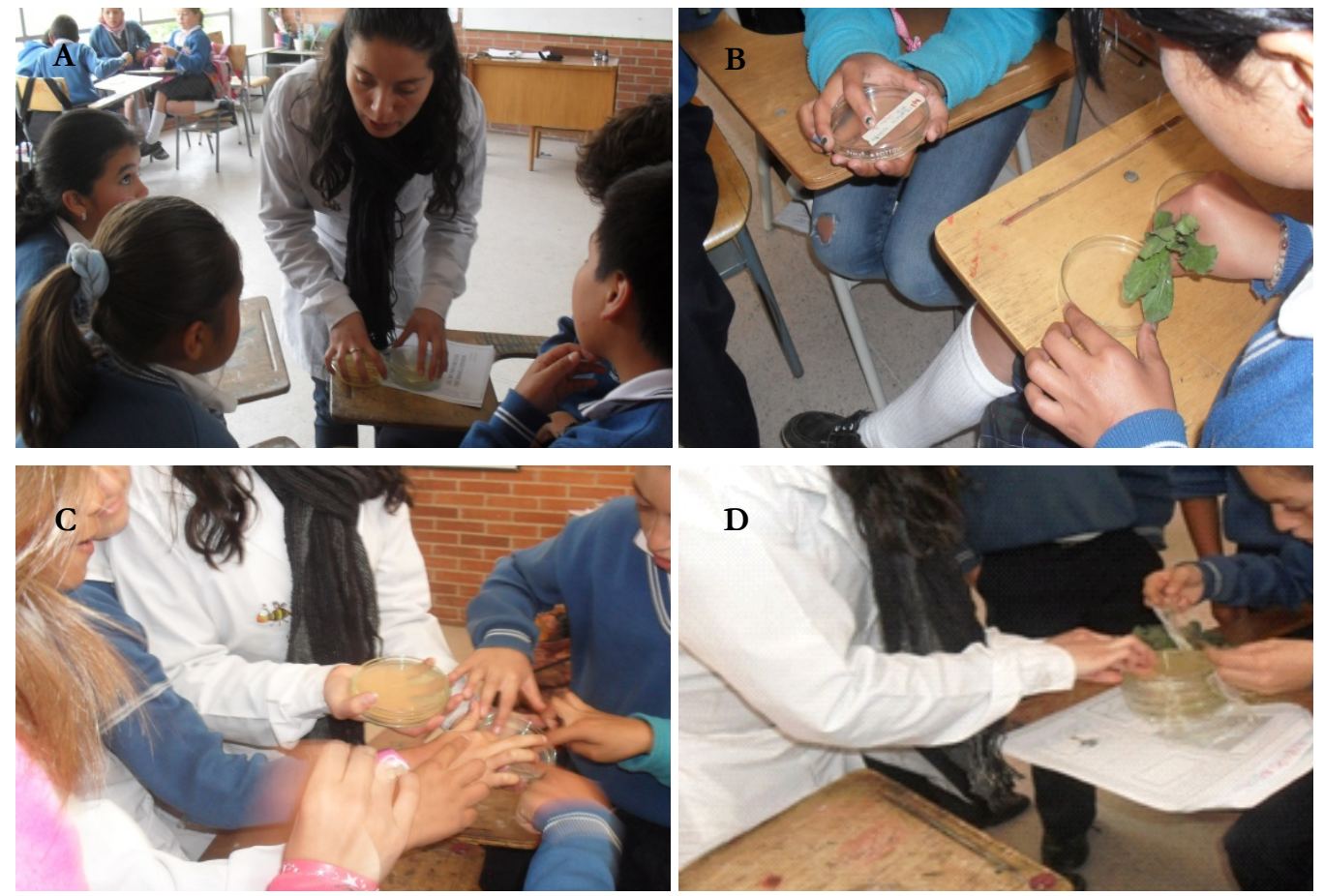

Figura 3. Momentos del desarrollo del módulo de aprendizaje. A: Docente proporcionando indicaciones de la práctica. B: Observacion de plantula. C: Estudiantes pasando los dedos en medios de cultivo. D: Estudiante pasando las raíces de una planta en el medio de cultivo.

\section{Sesión 3. Reconocer los microorganismos desde la descripción macroscópica de las cajas inoculadas}

Los estudiantes indican características de lo observado en las cajas de petri, describen forma, tamaño, color, textura, cuentan puntos de colonias de bacterias de cada color. Una vez realizado los cultivos, cada uno de los grupos analiza las cajas de Petri y efectúan descripciones como la siguientes: las colonias de las bacterias son verdes; hay 12 colonias de hongos verdes, 27 naranjas, 1 roja, 7 grises. Por ejemplo, el equipo F indica: En la caja de Petri se observa una mancha blanca, 
también "unos punticos semiredondos de color verde, rosados, amarillos y con hongo en la mitad". Equipo C "Nuestra caja esta con mucho agar nutritivo porque tiene 10 punticos anaranjados uno negro y 14 blancos".
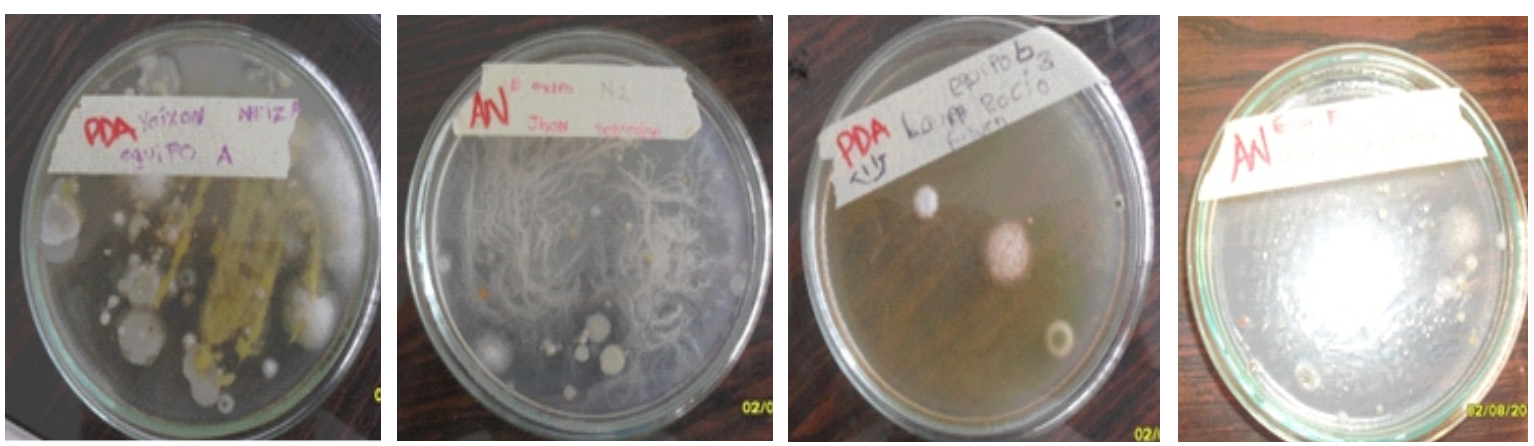

Figura 4. Práctica realizada con los niños en los medios de cultivo (PDA y AN).

Los estudiantes identificaron en primer lugar a los hongos y dedujeron que lo demás eran bacterias, lo anterior porque asociaron la textura algodonosa que presentan los hongos de los alimentos que se descomponen. Seguidamente, se hizo una aclaración de quienes pertenecían a las bacterias y a hongos, teniendo en cuenta la forma y aclarando que una agrupación de bacterias se les denomina colonia; se trabajaron temas como la reproducción y los nutrientes que requieren.

La figura 5, presenta algunos de los microorganismos representados por los estudiantes al observarlos al microscopio, luego de realizar las siembras en los medios de cultivo; por ejemplo, se dibujó una colonia de bacterias, como representación de las bacterias presentes en la cavidad bucal. Al respecto, las docentes aclaran que, desde el nacimiento del individuo, la cavidad bucal está expuesta a innumerables microorganismos presentes en el ambiente, estos se convierten en residentes de la cavidad bucal, y se ven favorecidos por las condiciones fisiológicas y nutricionales. También, los estudiantes representan las bacterias que frecuentemente se encuentran en la flora cutánea. La piel humana normal se encuentra colonizada por múltiples microorganismos que viven como saprófitos en la superficie, entre las escamas del estrato córneo y dentro de los folículos pilosos, los cuales en algunas ocasiones pueden volverse patógenos, (Santamaría y Alvarado 2002).
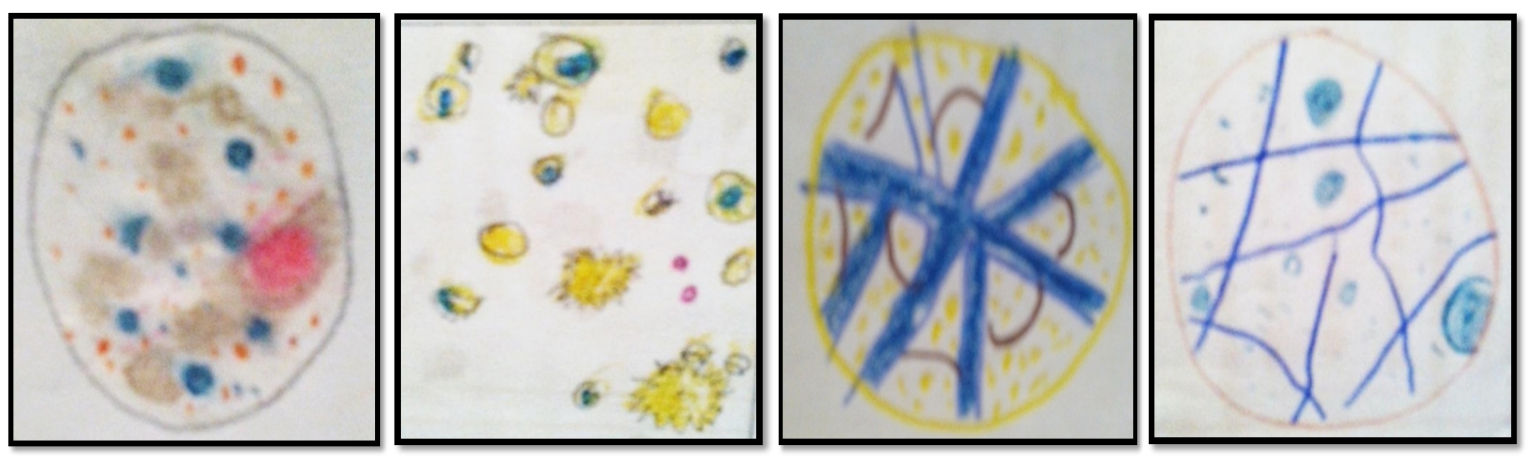

Figura 5. Representación gráfica de la vista microscópica de hongos y bacterias.

Sesión 4. Beneficios e implicaciones de los microorganismos

Se presentó a los estudiantes un video sobre los "Efectos de las bacterias promotoras de crecimiento en cultivos de quinua (Chenopodium quinoa)", desde el trabajo desarrollado en el componente biológico de este estudio. Al respecto algunos estudiantes hicieron comentarios como E13: la quinua se puede consumir sin ningún inconveniente asi tenga bacterias, debido a que estas son buenas y no producen enfermedades ni contraindicaciones en el organismo. E17. Esas bacterias (Refiriéndose a las rizo bacterias) pueden favorecer los buenos componentes de la quinua. E19. Me parece algo muy bueno, que beneficia al suelo y les permite aumentar su crecimiento y los protege de otros organismos. 
También, los estudiantes plantearon preguntas como ¿Las plantas no se enfermaron con la bacteria? ¿Las bacterias se pueden comer, en la quinua? ¿Cómo nacieron las bacterias? Se evidencia algunas intervenciones como:

- Las bacterias y bongos ayudan a bacer queso y los microorganismos son buenos porque sirven para hacer alimentos y medicamentos.

- Las bacterias promotoras de crecimiento ayudan a que crezcan las plantas y un alimento como la quinua da muchos beneficios como: minerales, proteinas, vitaminas.

- La quinua es uno de los mejores alimentos, porque tienen vitaminas y es un alimento de los indígenas

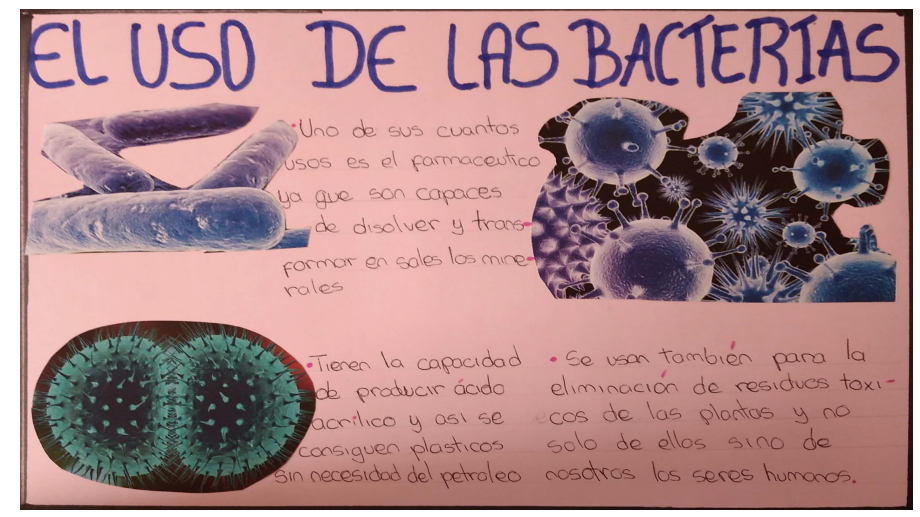

Figura 6. Representación sobre el uso de las bacterias.

En general, se observó un cambio positivo en los estudiantes, esto da cuenta que la información adecuada sobre los conceptos relacionados con la microbiología es importante para un cambio de concepciones sobre los microorganismos.

\section{Evaluación de la implementación del módulo de aprendizaje}

Los resultados del pos-test muestran una leve mejoría en la pregunta 1 , que hace referencia al concepto de microorganismos; sin embargo, se ven resultados satisfactorios en las preguntas, 3,4 y 5 sobre reproducción, beneficio de los microrganismos y conocimiento de la quina, donde el valor de $p$, muestra cambios significativos, según la prueba de Fisher; por ejemplo, la pregunta 5 obtuvo un $p=0,0000335$.

La figura 7, presenta la comparación de los valores en pre-test y post-test.

Estudiantes con respuesta acertadas en cada pregunta en pre- y post-test

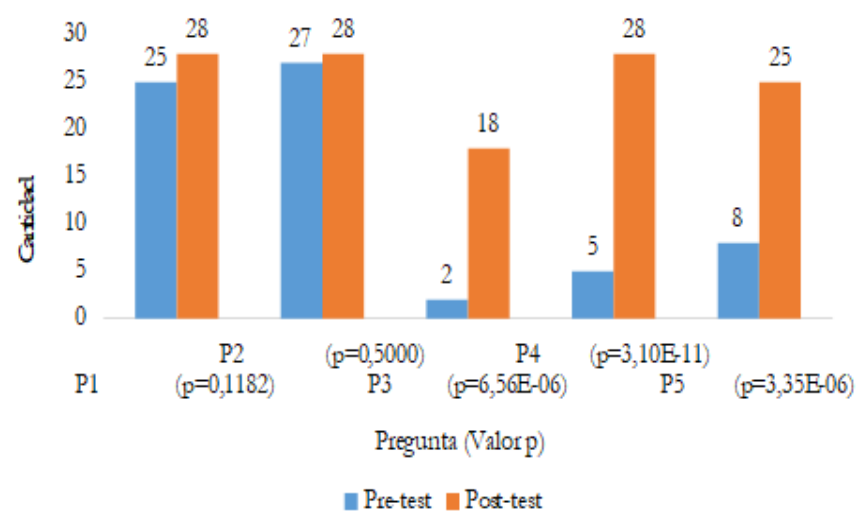

Figura 7. Comparación de los valores en pre-test y post-test.

En el cuestionario inicial, alrededor del $70 \%$ de los estudiantes dibujaron hongos a nivel macroscópico, asociándolos con representaciones de las consecuencias de infectarse con uno 
de ellos. Mientras en el cuestionario final, los estudiantes graficaron lo observado en las cajas de Petri y en el microscopio. Esto demuestra una contribución a identificar las condiciones para el desarrollo de los microorganismos como lo realizaron algunos estudiantes que dibujaron cajas de Petri con algunas colonias bacterianas y describieron sus beneficios hacia las plantas, Por ejemplo, E23 indica El uso de las bacterias es bueno porque ayudan al crecimiento de las plantas y éstas ayudan a nuestro cuerpo.

Con relación a la tercera pregunta, donde se cuestionaba sobre el tipo de reproducción de los microorganismos, en la prueba diagnostico el 54\% de los estudiantes contestaron que es sexual. Mientras que, en el cuestionario final, un 64,3\% responde reproducción asexual, 21,4\% de los estudiantes indican que los microorganismos se reproducen sexualmente y un 14,3\% creen que se reproducen por causa de la contaminación. Por lo tanto, se refleja una mejoría en los conceptos asociados, desde un cambio de reproducción sexual al asexual. Sin embargo, los resultados indican que es necesario trabajar en los mecanismos que tienen los microorganismos para su reproducción.

También pudo verse que los estudiantes utilizan palabras como esterilización, desinfección, medios de cultivo, agar aspecto que da cuentan de las aplicaciones de las prácticas de laboratorio que permiten ampliar, la visión de la microbiología en los niños. Cuando los estudiantes inocularon las cajas de Petri y observaron sus resultados tuvieron la oportunidad de identificar hongos y bacterias a nivel macroscópico y microscópico que les permitió comprender que los hongos y las bacterias hacen parte de los microorganismos.

\section{Beneficios de las bacterias}

Luego del desarrollo del módulo de aprendizaje, los estudiantes describen los beneficios de los microorganismos, y hacen afirmaciones como E13: Los microorganismos sirven para la fabricación de alimentos, de medicamentos y para el crecimiento de plantas como es el caso de la quinua. E28: Es una excelente función que tienen las bacterias, porque la quinua al ser una planta tiene bacterias que eliminan sus residuos tóxicos, lo que la hace un mejor alimento para curar diferentes enfermedades. E9. Aprendí que las bacterias sirven para hacer antibióticos para tratar diversas enfermedades.

En el diagnostico se evidenció la poca comprensión que los niños presentan sobre la quinua, no diferenciaban si es planta, animal o bacteria, luego de la intervención didáctica se reflejan algunas respuestas como E7: La quinua es una planta y es el alimento de la nasa, E17: La quinua es una planta que tiene muchos nutrientes que nos ayudan a reforzar nuestro cerebro. E6. La quinua es una planta que produce una semilla pequeña que sirve para alimentarnos.

\section{Conclusiones}

El desarrollo del módulo les permitió a los estudiantes conocer que los microorganismos son hongos y bacterias, también se aclaro procesos de reproducción asexual y sexual, así como las condiciones necesarias para su reproducción. Una de las intencionalidades del módulo didáctico era mostrar las utilidades de las bacterias en el crecimiento de las plantas en específico de la quinua, aspecto que se logró y fue corroborado en los resultados del pos-test.

Los estudiantes al principio consideraban que los hongos y las bacterias son agentes dañinos y nocivos causantes de enfermedades que no ofrecen ningún beneficio; al final de la intervención tienden a reconocer que hay microorganismos benéficos para el ser humano como por ejemplo su contribución en el crecimiento de las plantas.

Los estudiantes también aprendieron por observación directa que las bacterias no solo crecen en medio ambiente en los desperdicios y en la tierra, sino también pueden crecer en medios de cultivo. 
Finalmente se considera necesario continuar con temas relacionados a la enseñanza de la microbiología desde los escenarios de educación primaria, dado que acerca a los estudiantes al conocimiento de la biotecnología y sus implicaciones en aspectos como fabricación de alimentos, medicamentos y mejoramiento de especies vegetales. De igual manera, los estudiantes tienen la posibilidad de conocer la forma de trabajo de los microbiólogos aspecto importante para promover actitudes positivas en el desarrollo de carreras científicas.

\section{Referencias}

Acevedo-Díaz, J. A., García-Carmona, A., Aragón, M. D. M. (2016) La controversia Pasteur vs. Pouchet sobre la generación espontánea: un recurso para la formación inicial del profesorado en la naturaleza de la ciencia desde un enfoque reflexivo. Ciência \& Educação (Bauru), 22(4), 913-933.

Ballesteros, M. I., Paños, E., Ruiz, J. R. (2018). Los microorganismos en la educación primaria: ideas de los alumnos de 8 a 11 años e influencia de los libros de texto. Enseñanza de las ciencias, 36(1),79-98. https://doi.org/10.5565/rev/ensciencias.2274

Begum N., Qin C., Ahanger M. A., Raza S., Khan M. I., Ashraf M., Ahmed N., Zhang L. (2019) Role of Arbuscular Mycorrhizal Fungi in Plant Growth Regulation: Implications in Abiotic Stress Tolerance. Frontiers in Plant Science, 10, 1-15. https://doi.org/10.3389/fpls.2019.01068

Byrne J., Grace M., Hanley P. (2009) Children's anthropomorphic and anthropocentric ideas about micro-organisms. Journal of Biological Education, 44(1), 37-43. https://doi.org/10.1080/00219266.2009.9656190

Camelo R., M., Vera M., S. P., Bonilla B., R. R. (2011) Mecanismos de acción de las rizobacterias promotoras del crecimiento vegetal. Corpoica Ciencia y Tecnología Agropecuaria, 12(2), 159. https://doi.org/10.21930/rcta.vol12_num2_art:227

Durango M. (2012) La microbiologia en la escuela: una experiencia didáctica aplicada a séptimo grado de educación basica. Tesis de Maestria. Universidad Nacional de Colombia. 1-71. http://www.bdigital.unal.edu.co/8318/2/la_microbiologia_en_la_escuela,_una_propu esta_didactica_aplicada_a_septimo_grado_de_educacion_basica.pdf

Faccio E., Costa N., Losasso C., Cappa V., Mantovani C., Cibin V., Andrighetto I., Ricci A. (2013) What programs work to promote health for children? Exploring beliefs on microorganisms and on food safety control behavior in primary schools. Food Control, 33(2), 320-329. https://doi.org/10.1016/j.foodcont.2013.03.005

García-Parra M., Zurita-Silva A., Stechauner-Rohringer R., Roa-Acosta D., Jacobsen S. E. (2020) Quinoa (Chenopodium quinoa willd.) and its relationship with agroclimatic characteristics: A colombian perspective. Chilean Journal of Agricultural Research, 80(2), 290-302. https://doi.org/10.4067/S0718-58392020000200290

Harms U. (2002) Biotechnology education in schools. Electronic Journal of Biotechnology, 5(3), 205-211. https://doi.org/10.2225/vol5-issue3-fulltext-i03

Jones M. G., Rua M. J. (2006) Conceptions of germs: Expert to novice understandings of microorganisms. Electronic Journal of Science Education, 10(3), 1-40.

Karadon H. D., Şahin N. (2010) Primary school students' basic knowledge, opinions and risk perceptions about microorganisms. Procedia - Social and Behavioral Sciences, 2(2), 43984401. https://doi.org/10.1016/j.sbspro.2010.03.700 
Liu Z., Ma, S., Cao G., Meng C., He B. J. (2018) Distribution characteristics, growth, reproduction and transmission modes and control strategies for microbial contamination in HVAC systems: A literature review. Energy and Buildings, 177, 77-95. https://doi.org/10.1016/j.enbuild.2018.07.050

Marcos-Merino J., Gallego R., Ochoa de Alda, J. (2019) Formando a futuros maestros para abordar los microorganismos mediante actividades prácticas. Papel de las emociones y valoraciones de los estudiantes. Revista Eureka, 16, 1602-1618. https://doi.org/10.25267/Rev_Eureka_ensen_divulg_cienc.2019.v16.11.1602

Milandri M. (2004) Children's Views of Microbes: Current Beliefs About Bacteria in Italian Grade School Children. The Pediatric Infectious Disease Journal, 23(12). https://journals.lww.com/pidj/Fulltext/2004/12000/Children_s_Views_of_Microbes _Current_Beliefs.2.aspx

Montaño N. M., Sandova A. L., Camargo S. L., Sánchez Yáñez, J. M. (2010) Los microorganismos: pequeños gigantes. Revista Ciencia y Cultura Elementos, 77(0187-9073), 15-23. https://www.redalyc.org/pdf/294/29411989003.pdf

Moreno A., García V., Reyes J. L., Vásquez , J., Cano, P. (2018) Rizobacterias promotoras del crecimiento vegetal: una alternativa de biofertilización para la agricultura sustentable. Revista Colombiana de Biotecnología, 20(1), 68-83. https://doi.org/10.15446/rev.colomb.biote.v20n1.73707

Pedraza R. O., Teixeira K. R. S., Scavino A. F., De Salamone I. G., Baca, B. E., Azcón R., Baldani V. L. D., Bonilla, R. (2010) Microorganismos que mejoran el crecimiento de las plantas y la calidad de los suelos. Revisión. Corpoica Ciencia y Tecnología Agropecuaria, 11(2), 155. https://doi.org/10.21930/rcta.vol11_num2_art:206

Pedreros E; Torres, N. (2020) Espaços não formais de ensino: potencializando a aprendizagem. En. Strohschoen, Andreia Aparecida Guimarães; Schwarzer, Carla Heloísa; Silva, Jacqueline Silva da; Martins, Silvana Neumann. V. Henckes, Simone Beatriz Recziegel(Orgs.). Aprender sobre adaptación desde el museo de historia natural en el contexto de la educación básica primaria, pp 32-43- Lajeado: Editora Univates.

Pérez U. A., Ramírez M. M., Zapata, Y. A., Córdoba, J. M. (2015) Efecto de la inoculación simple y combinada con Hongos Formadores de Micorriza Arbuscular (HFMA) y Rizobacterias Promotoras de Crecimiento Vegetal (BPCV) en plántulas micropropagadas de mora (Rubus glaucus L.). Corpoica Ciencia y Tecnología Agropecuaria, 16(1), 95. https://doi.org/10.21930/rcta.vol16_num1_art:383

Redfern J., Burdass D., Verran J. (2013) Practical microbiology in schools: A survey of UK teachers. Trends in Microbiology, 21(11), 557-559. https://doi.org/10.1016/j.tim.2013.09.002

Santamaría V., Alvarado A. (2002) Flora cutánea como protección y barrera de la piel normal. Rev Cent Dermatol Pascua, 11(1), 18-21. http://www.medigraphic.com/pdfs/derma/cd2002/cd021e.pdf

Siegel S., Castellan J. (1998) Estadística no paramétrica. E-Conversion - Proposal for a Cluster of Excellence, 129-131.

Torres, N. Y., Salcedo, L. A., Becerra, Á.,Valderrama, W. (2018) Fuentes de conocimiento en la identificación y preferencias de fauna en niñez de contextos rurales y urbanos. Revista Electrónica Educare, 22(3), 1-17. https://doi.org/10.15359/ree.22-3.4

Williams R. P., Gillen, A. L. (1991). Microbe Phobia \& Kitchen Microbiology. American Biology Teacher, 53(1), 10-11. https://doi.org/10.2307/4449204 